\title{
Assessing performance of Morningstar's star rating system for equity investment
}

\author{
Paul J. Bolstera*, Emery A. Trahan ${ }^{b}$, Pinshuo Wangc \\ a CFA, Professor of Finance, D'Amore-McKim School of Business, Northeastern University, Boston, MA 02115. \\ b CFA, Senior Associate Dean, D’Amore-McKim School of Business, Northeastern University, Boston, MA 02115. \\ c Ph.D. Candidate, Department of Economics, College of Social Studies and Humanities, Northeastern University \\ *Corresponding author's email address: p.bolster@neu.edu
}

\section{ART T C LE INF O}

Received: 16-02-2016

Accepted: 29-02-2016

Available online: 02-03-2016

Keywords:

Asset pricing,

investment decisions,

ratings and rating agencies,

security analyst.

JEL Classification:

G240, G110, G120, G140.

\begin{abstract}
A B S T R A C T
Both institutional and individual investors have a vast array of advisory and ratings services to assist with security selection. One of the most prominent sources of stock ratings is Morningstar. This is the first large-scale study evaluating the performance of portfolios formed using Morningstar's Star rating system for stocks. We evaluate the performance of portfolios formed using this rating system. Our results provide evidence that the Morningstar stock rating system allows an investor to build a portfolio with superior absolute and risk-adjusted returns over a long period of time. We show that a modest transaction cost will reduce, but not eliminate, these benefits. Overall, our results indicate that Morningstar ratings effectively discriminate between over- and undervalued stocks over the long term.
\end{abstract}

(C) 2016 The Authors. This is an open access article under the terms of the Creative Commons Attribution License 4.0, which allows use, distribution and reproduction in any medium, provided the original work is properly cited.

DOI: http://dx.doi.org/10.18533/jefs.v4i1.214

\subsection{Introduction}

Individual investors are frequently searching for convenient and inexpensive advice regarding security selection and portfolio construction. One of the most prominent providers of such advice is Morningstar. This firm is best known for its ratings of a very large number of U.S.-based mutual funds. However, Morningstar also provides ratings of individual stocks. In this study, we address the following basic question: Can an investor employ these stock ratings to create a portfolio with superior performance?

There is a rich and varied literature in academic finance indicating that markets are essentially efficient in the semi-strong sense. In other words, once a recommendation or rating becomes public, any information it conveys is immediately incorporated into market prices. By the time the investor reads and reacts to the information, it is too late to exploit it. Numerous studies of national financial publications, independent newsletters and established rating services routinely conclude there is no material benefit in terms of investment returns. However, there are other studies, particularly those focused on analyst ratings of individual stocks that have found positive returns.

In this study, we employ the historical record of all Morningstar stock ratings over a period of approximately eleven years, nearly 140,000 unique ratings. We construct five portfolios, corresponding to the five "star" categories employed by Morningstar's stock rating system. Our analysis shows that the Morningstar stock rating system is able to effectively distinguish between the most overvalued (1-star) and undervalued (5-star) stocks. 
Based on risk-adjusted returns, a portfolio of 5-star stocks outperformed a portfolio of 1-star stocks in 8 of 12 years from 2001 to 2012 and by $173.42 \%$ in unadjusted cumulative returns over our entire period of analysis.

We employ a Fama-French model to further assess sources of returns for the five portfolios. This analysis shows that the style characteristics of the five portfolios, particularly the 1-star and 5-star portfolios, vary widely during the 11 years of our study. Our results indicate that individual investors could benefit by properly exploiting the information provided in Morningstar's stock ratings. Return differences between the highest and lowest rated stocks are substantial and persist even after adjustment for risk and transaction costs.

The remainder of the study proceeds as follows. Section 2.0 provides an overview of empirical studies assessing the value of published investment advice. Section 3.0 provides a background of investor services provided by Morningstar. This is followed by a detailed discussion of data and methodology in section 4.0. Results of our analysis and conclusions appear in sections 5.0 and 6.0 respectively.

\section{$2.0 \quad$ Review of literature}

There is an extensive literature assessing the value of investment advice in general and stock ratings systems in particular. Several studies provide examples of the former. Metrick (1999) evaluates the performance of 153 investment newsletters and finds no case for outperformance. Dewally (2003) reports that stock recommendations distributed by major newsgroups through internet discussion forums produce no abnormal performance in the short or long term. Bolster, Trahan and Venkateswaran (2012) evaluate a large sample of stock recommendations made by the popular investment guru, Jim Cramer and conclude that his performance is in line with the risk level of his picks.

There is also considerable prior work examining the value of stock rating systems. Among the earliest studies, Black (1973) found that a portfolio formed from the top rated stocks on Value Line produced significant excess returns over a five year period from 1965 to 1970 even when adjusting for transaction costs. However, a study of Value Line rankings by Hall and Tsay (1988) found that top rated stocks did not provide significant excess returns during the period from 1976 to 1982. The disappearance of a Value Line premium is consistent with the major conclusion of a recent study of 95 pricing anomalies by McLean and Pontiff (2014). They find that returns attributed to most pricing anomalies are significantly reduced after their presence is reported in a publication.

Another common approach among studies of stock ratings exploits the system used by analysts where ratings of 1 to 5 represent strong buy, buy, hold, sell, and strong sell, respectively. Barber, Lehavy, McNichols and Trueman (2001) find that a strategy of shorting the lowest rated stocks generates superior returns. However, they also report that these returns may be eliminated by transaction costs. A more recent study, also by Barber, Lehavy, McNichols and Trueman (2010), shows that a portfolio that is long all buy and strong buy stocks and short all sell and strong sell stocks will produce positive and significant abnormal returns. The abnormal returns would be materially higher if this portfolio was further conditioned to focus on only stocks being upgraded to buy or strong buy or downgraded to sell or strong sell.

There are many studies of Morningstar's mutual fund ratings but there is very little published analysis of Morningstar's stock rating system. Examples of these studies include Blake and Morey (2000) who find predictive power in ratings, especially for the lowest rated funds, and DelGurico and Tkac (2001) who document a strong relationship between fund flows and changes in a fund's Morningstar rating.

Nearly all of the aforementioned studies pose a question similar to the one we pose here: Can an investor employ publically available information provided by an investment advisory firm to create a portfolio with superior performance? While the empirical finance literature generally supports the paradigm of semi-strong form market efficiency, there are a number of studies showing that publically available information can be used to generate positive, risk adjusted returns. Our study, which we believe is the first to comprehensively examine the efficacy of Morningstar's 5-star stock rating system, provides such a test.

\subsection{About Morningstar}

Morningstar was founded in 1984 by Joe Mansueto to provide individual investors with mutual fund analysis and commentary. Its first product was The Mutual Fund Sourcebook ${ }^{\mathrm{m}}$, a quarterly publication containing performance data, portfolio holdings, and other information on approximately 400 mutual funds. Today, Morningstar claims to be one of the most recognized and trusted names in the investment industry, serving more than 7.4 million individual investors, 270,000 financial advisors, and 4,300 institutional clients. 
On its website Morningstar.com, Morningstar, Inc. touts itself as a "leading provider of independent investment research in North America, Europe, Australia, and Asia; offering an extensive line of products and services for individuals, financial advisors, and institutions." The company provides data on more than 380,000 investments, including stocks, mutual funds and other types of funds, along with real-time global market data on more than eight million equities, indexes, futures, options, commodities, precious metals, foreign exchange, and Treasury markets. Morningstar also offers investment management services, with over of $\$ 190$ billion assets under management or advisement and operations in 27 countries.

Morningstar offers products and services to advisors, institutions and individual investors. Much of their service is targeted toward providing independent information and advice to individual investors. Their website states that "individuals use Morningstar to make educated investment decisions. These investors want all the pertinent facts, as well as the assurance that their information source is completely independent." The company lists various attributes that relate to its ability to deliver world-class investment research and services. These attributes include, investor focus (maintaining an independent view and designing products to help investors make wellinformed investment decisions); depth, breadth, and accuracy of data (employing 270 analysts worldwide and providing information on approximately 330,000 investment offerings); innovative, proprietary investment tools (e.g., Morningstar Rating ${ }^{\mathrm{m}}$, Morningstar Style Box ${ }^{\mathrm{m}}$, Morningstar Ownership Zone ${ }^{\mathrm{m} m}$, and a proprietary sector classification system for stocks); and finally, research and technology expertise (striving to rapidly adopt new technology and providing a flexible technology platform allowing products to work together). The primary tool for individual investors is Morningstar.com ${ }^{\circledR}$, which Morningstar claims consistently ranks among the best investment sites on the web.

In 1985, shortly after its founding, Morningstar released its now famous Morningstar Rating ${ }^{\text {tw }}$ for mutual funds, using the familiar rating of from one to five stars. In 1988, the company expanded into analysis of individual stocks, launching its Morningstar ${ }^{\circledR}$ StockInvestor ${ }^{\text {tw }}$ newsletter. In 2001, Morningstar launched its Morningstar rating for individual stocks. Similar to its ratings of mutual funds, the Morningstar rating for stocks assigns each stock a rating of from one to five stars. A stock's rating is driven by its level of expected return, with 5-star stocks being those expected to offer investors returns well above a company's cost of capital.

\subsection{Data and methodology}

Morningstar analysts cover over 1800 companies in more than 100 industries, including more than $85 \%$ of the market value of the Wilshire 5000 Index. Morningstar evaluates each company as a business and conducts a fundamental analysis valuation considering how much capital a company invests and its return on capital, free cash flow, growth, and sources of competitive advantage and the likely fade in returns as competitive advantages erode over time. It examines each company using a discounted cash flow model and computes the value as the present value of the company's expected future free cash flows discounted at its cost of capital.

Morningstar analysts compare each company's fair value estimate to its market value and assign a rating of from one to five stars. Stocks trading at large discounts to fair value receive higher (4 or 5) star ratings, while those trading at large premiums to fair value estimates receive lower (1 or 2) star ratings. Stocks trading close to fair value receive 3-star ratings. Risk is also factored into the rating so that the greater the uncertainty of the stock, the greater its discount to fair value needs to be to earn a 5-star rating. A 5-star rating can be interpreted as a "consider buying" recommendation, i.e., the price of the stock is below the fair value by a sufficient margin to be purchased. Morningstar also advises individuals to consider their circumstances, including diversification, risk tolerance, and tax considerations.

Ratings are updated daily and therefore may change daily. Ratings can change due to: 1) a movement in the stock's price, 2) a change in the analyst's estimate of the stock's fair value, 3) a change in the analyst's assessment of a company's business risk, or 4) a combination of these factors. It should be noted that the Morningstar stock ratings are fundamentally different than the star ratings for mutual funds. The mutual fund ratings are descriptive, backward-looking, based on historical performance, strictly quantitative, calculated once a month, and rank funds according to a fixed distribution (i.e., only $10 \%$ of the funds in each category can receive 5 -star ratings). The ratings for stocks are based on forward-looking estimates, adjusted for uncertainty, based on quantitative and qualitative inputs, calculated daily, and do not rank stocks according to a fixed distribution. Dorsey (2008) provides a more complete description of the Morningstar rating system for stocks.

Table 1 shows the number and proportion of stocks in each rating category at the end of each year from 2001 to 2012. We note that the number of stocks rated climbs from a low of 469 in 2001 to a high of 2107 in 2008 before tapering off to 1897 in 2012. But the most interesting element of this table relates to the proportion of stocks in each star category. Three-star stocks comprise the greatest proportion of the sample of rated stocks in every year, 
ranging from $33.75 \%$ to $56.09 \%$. Stocks in this category are considered "fairly valued", a neutral rating. The proportion of 5-star stocks ranges from a low of $3.74 \%$ to a high of $24.82 \%$. The high proportion occurs at the end of 2008, a fantastically bad year for the U.S. equity market. Conversely, the proportion of 1-star stocks is at its lowest point, $2.18 \%$ in 2008 . This suggests that the depressed values for stocks at this time indicated a disproportionate number of bargains and relatively few overvalued securities.

Our main source of data is assembled from daily reports of stock ratings for Morningstar's entire sample of rated stocks. The data begins on June 26, 2001 and ends on October 1, 2012. The number of rated stocks varies over time and is 1897 at the end of our period of analysis. This data set allows us to identify (1) whether a stock is rated, (2) a stock's rating on a particular trading day, and (3) the day of a change in a stock's rating. Using this data we are able to identify 144,083 individual rating changes. After merging this database with CRSP to obtain stock returns, we retained 139,636 useable rating changes.

The CRSP data we employ measures daily total returns for individual stocks using closing prices. We create portfolios comprised of stocks with a specific rating using two different approaches. The first approach derives a simple arithmetic average, or equal weighted (EW) return for stocks assigned to a particular star portfolio for each of the 2,835 trading days in our sample period. Analysis of these returns should give us insight into whether the rating system is an effective discriminator on average.

On the other hand, perhaps all ratings are not equally informative. For example, what if some 5 -star stocks perform incredibly well while most perform just a bit better than average? In this scenario, the EW return would underreport the effectiveness of the 5-star rating from an investor's perspective. Alternatively, maybe most 5-star stocks do a bit better than average but a minority perform poorly. In this case, the EW return would exaggerate the return that an investor who maintained a consistent portfolio of 5-star stocks would actually achieve. Furthermore, an EW portfolio would not be investable in any practical way. To adjust for possible asymmetry in performance and to create a more investable portfolio, we create a series of dollar weighted (DW) returns for each of our five portfolios.

\begin{tabular}{|c|c|c|c|c|c|c|}
\hline \multicolumn{7}{|c|}{ Table 1: Distribution of Star Ratings by Year } \\
\hline Year & 1-star & 2-star & 3-star & 4-star & 5-star & Total \\
\hline \multirow[t]{2}{*}{2001} & 78 & 98 & 180 & 85 & 28 & 469 \\
\hline & $16.63 \%$ & $20.90 \%$ & $38.38 \%$ & $18.12 \%$ & $5.97 \%$ & \\
\hline \multirow[t]{2}{*}{2002} & 66 & 88 & 254 & 65 & 86 & 559 \\
\hline & $11.81 \%$ & $15.74 \%$ & $45.44 \%$ & $11.63 \%$ & $15.38 \%$ & \\
\hline \multirow[t]{2}{*}{2003} & 150 & 152 & 216 & 59 & 63 & 640 \\
\hline & $23.44 \%$ & $23.75 \%$ & $33.75 \%$ & $9.22 \%$ & $9.84 \%$ & \\
\hline \multirow[t]{2}{*}{2004} & 386 & 226 & 527 & 111 & 59 & 1309 \\
\hline & $29.49 \%$ & $17.27 \%$ & $40.26 \%$ & $8.48 \%$ & $4.51 \%$ & \\
\hline \multirow[t]{2}{*}{2005} & 353 & 201 & 684 & 218 & 98 & 1554 \\
\hline & $22.72 \%$ & $12.93 \%$ & $44.02 \%$ & $14.03 \%$ & $6.31 \%$ & \\
\hline \multirow[t]{2}{*}{2006} & 384 & 208 & 826 & 271 & 101 & 1790 \\
\hline & $21.45 \%$ & $11.62 \%$ & $46.15 \%$ & $15.14 \%$ & $5.64 \%$ & \\
\hline \multirow[t]{2}{*}{2007} & 255 & 148 & 765 & 424 & 382 & 1974 \\
\hline & $12.92 \%$ & $7.50 \%$ & $38.75 \%$ & $21.48 \%$ & $19.35 \%$ & \\
\hline \multirow[t]{2}{*}{2008} & 46 & 78 & 792 & 668 & 523 & 2107 \\
\hline & $2.18 \%$ & $3.70 \%$ & $37.59 \%$ & $31.70 \%$ & $24.82 \%$ & \\
\hline \multirow[t]{2}{*}{2009} & 98 & 407 & 1169 & 319 & 91 & 2084 \\
\hline & $4.70 \%$ & $19.53 \%$ & $56.09 \%$ & $15.31 \%$ & $4.37 \%$ & \\
\hline \multirow[t]{2}{*}{2010} & 106 & 510 & 1041 & 298 & 76 & 2031 \\
\hline & $5.22 \%$ & $25.11 \%$ & $51.26 \%$ & $14.67 \%$ & $3.74 \%$ & \\
\hline \multirow[t]{2}{*}{2011} & 100 & 336 & 793 & 565 & 154 & 1948 \\
\hline & $5.13 \%$ & $17.25 \%$ & $40.71 \%$ & $29.00 \%$ & $7.91 \%$ & \\
\hline \multirow[t]{2}{*}{2012} & 95 & 376 & 877 & 446 & 103 & 1897 \\
\hline & $5.01 \%$ & $19.82 \%$ & $46.23 \%$ & $23.51 \%$ & $5.43 \%$ & \\
\hline
\end{tabular}

To create the vector of DW returns, we invest $\$ 1$ in a stock as it initially enters its designated portfolio at the close of the market on the day Morningstar releases the new information. We believe the closing price incorporates any short-term information effects of the disclosure of the rating change itself and better focuses the analysis on the continued performance of the portfolio. The stock remains in its designated portfolio until Morningstar assigns it a different rating. When a stock is reassigned to a new portfolio, we remove all accumulated value the original $\$ 1$ investment has produced from the old portfolio and invest $\$ 1$ in the new portfolio. 
Here is a more concrete explanation of the rebalancing process for the DW portfolio. Morningstar announced an upgrade of Comcast from 4-star to 5-star on the morning of April 10, 2008. We invest $\$ 1$ in Comcast at the market close on that day. We then use CRSP daily returns to revalue our investment in Comcast at the end of each subsequent trading day. On April 30, 2008, Comcast was downgraded from 5-star to 4-star. As of the close of the market on that day, our original $\$ 1$ investment had grown to $\$ 1.0296$. At this point, we calculate the aggregate value of all securities in the 5-star portfolio and the daily return for April 30. We then deduct $\$ 1.0296$ from the aggregate value of the 5-star portfolio and also adjust for any other entries into or exits from the portfolio. The resulting adjusted aggregate value becomes the beginning value used to calculate the May 1, 2008 daily return.

In addition to evaluating raw returns, we also use the 4-factor Fama-French model to create risk-adjusted returns for both EW and DW approaches. This approach allows us to examine differential performance among the five portfolios formed from Morningstar's ratings and also to observe differences in style, or factor exposures across the portfolios and over time.

\section{$5.0 \quad$ Results}

\subsection{Portfolio performance}

Table 2 provides basic data on average daily returns by star rating for both EW and DW portfolios. For the EW portfolios, shown in Panel A, the 5-star portfolio outperforms the 1-star portfolio in 9 of 12 years. This difference is positive and significant in 2003 and 2010 and negative and significant in 2007. Across all 2835 days in our sample, the 5-star portfolio outperformed the 1-star by an average of 2.05 bps per day. This difference is not statistically significant. Overall, the 5-star portfolio provided the highest daily average return of 7.00 bps. However, the 4 and 1-star portfolios nearly tied for second place with 5.00 and 4.95 bps per day respectively.

Panel B shows returns for the DW portfolios. While the figures are different, the results are quite similar in a relative sense. The 5-star portfolio outperforms the 1-star portfolio in 8 of 12 years. The difference is positive and significant in 2003 and negative and significant in 2007. Over the entire sample, the average difference in daily returns was 1.12 bps higher for the 5-star, again not statistically significant. Again, the overall return for the 5star portfolio produced the highest average, $4.67 \mathrm{bps}$ per day. The performance of the five portfolios was nearly monotonic overall.

While the annual results provide modest support at best for superior performance of the 5 -star portfolio relative to the 1-star portfolio, the cumulative returns over the entire period provide a much stronger result. The cumulative EW return for the 5-star portfolio is $322.26 \%$ overall, or $13.66 \%$ annualized. The 1 -star portfolio returned $148.86 \%$ overall, or $8.44 \%$ annualized. Comparable returns for the DW portfolios were $127.89 \%$ overall ( $9.09 \%$ annualized) for the 5 -star and $62.37 \%$ overall (5.25\% annualized) for the 1 -star. It's also worth noting that there was no material difference in cumulative performance between the 5-star portfolio and the 3-star and 4-star portfolios. The differential performance of the five portfolios is illustrated in Figure 1.

\subsection{Basic risk metrics}

Analysis of cumulative returns clearly shows that investors who focused solely on 5-star stocks would outperform those focused solely on 1-star stocks. This could suggest that Morningstar's ranking model is able to effectively discriminate between the best and worst performers, at least on a relative basis. Alternatively the difference could be explained by characteristics of the 5 -star and 1-star portfolios.

Equal weighted portfolios are formed by calculating the arithmetic average return for all stocks carrying the specified ranking each day. Dollar weighted portfolios assume $\$ 1$ is invested in a stock as it enters a portfolio. The accumulated value of this investment is removed from the portfolio when the stock leaves the portfolio. The aggregate end of day value of all stocks in a specified star portfolio is then used to calculate the daily dollar weighted portfolio return. For both equal weighted and dollar weighted portfolios all rebalancing occurs at the end of the trading day. The rightmost column shows the differential return between the highest rated (5-star) and lowest rated (1-star) stock portfolios.

Table 2: Average daily returns for portfolios created based on star ratings (in basis points per day, or bps)

\begin{tabular}{lrrrrrr} 
& & \multicolumn{4}{c}{ Panel A: Equal Weighted portfolios } \\
\hline Year & 1-star & 2-star & 3-star & 4-star & 5 -star & 5 -1 \\
2001 & 1.24 & 3.15 & 2.66 & 0.75 & 3.88 & 2.64 \\
2002 & -19.14 & -14.23 & -7.07 & -5.09 & -16.32 & 2.83 \\
2003 & 15.55 & 14.63 & 16.29 & 19.41 & 31.22 & $15.67^{* * *}$ \\
2004 & 5.81 & 7.41 & 6.87 & 8.78 & 9.50 & 3.69 \\
2005 & 5.02 & 3.03 & 3.64 & 2.58 & 2.32 & -2.70
\end{tabular}




\begin{tabular}{|c|c|c|c|c|c|c|}
\hline 2006 & 6.93 & 6.54 & 7.16 & 8.17 & 9.97 & 3.03 \\
\hline 2007 & 4.35 & 3.44 & 2.44 & -1.18 & -4.18 & $-8.53^{*}$ \\
\hline 2008 & -15.42 & -19.78 & -18.51 & -16.53 & -10.65 & 4.77 \\
\hline 2009 & 39.11 & 16.65 & 22.96 & 26.64 & 32.00 & -7.11 \\
\hline 2010 & 9.03 & 11.99 & 10.67 & 10.63 & 17.09 & $8.06^{* *}$ \\
\hline 2011 & -3.67 & 1.24 & -1.43 & -3.44 & -2.14 & 1.53 \\
\hline 2012 & 10.07 & 6.96 & 7.42 & 7.99 & 10.78 & 0.71 \\
\hline Overall & 4.95 & 3.34 & 4.43 & 5.00 & 7.00 & 2.05 \\
\hline \multicolumn{7}{|c|}{ Panel B: Dollar Weighted portfolios } \\
\hline Year & 1-star & 2-star & 3-star & 4-star & 5-star & 5-1 \\
\hline 2001 & -0.30 & 1.64 & 2.02 & 0.63 & 0.55 & 0.85 \\
\hline 2002 & -20.70 & -13.66 & -8.11 & -6.11 & -23.78 & -3.07 \\
\hline 2003 & 15.89 & 15.57 & 16.28 & 17.57 & 24.37 & $8.49^{* *}$ \\
\hline 2004 & 6.79 & 6.97 & 7.29 & 8.87 & 7.29 & 0.50 \\
\hline 2005 & 5.58 & 3.18 & 3.75 & 3.10 & 3.10 & -2.49 \\
\hline 2006 & 6.47 & 6.38 & 6.97 & 8.43 & 9.32 & 2.84 \\
\hline 2007 & 4.60 & 3.35 & 2.38 & -0.95 & -3.70 & $-8.30^{*}$ \\
\hline 2008 & -19.39 & -16.65 & -20.28 & -17.73 & -10.91 & 8.48 \\
\hline 2009 & 27.26 & 14.68 & 20.59 & 23.12 & 25.75 & -1.51 \\
\hline 2010 & 8.15 & 11.84 & 10.70 & 8.93 & 13.62 & 5.47 \\
\hline 2011 & -1.61 & 1.04 & -0.41 & -2.86 & -0.98 & 0.63 \\
\hline 2012 & 9.56 & 6.74 & 7.38 & 7.12 & 11.06 & 1.50 \\
\hline Overall & 3.55 & 3.42 & 4.05 & 4.26 & 4.67 & 1.12 \\
\hline
\end{tabular}

Figure 1: Cumulative returns for Star Portfolios
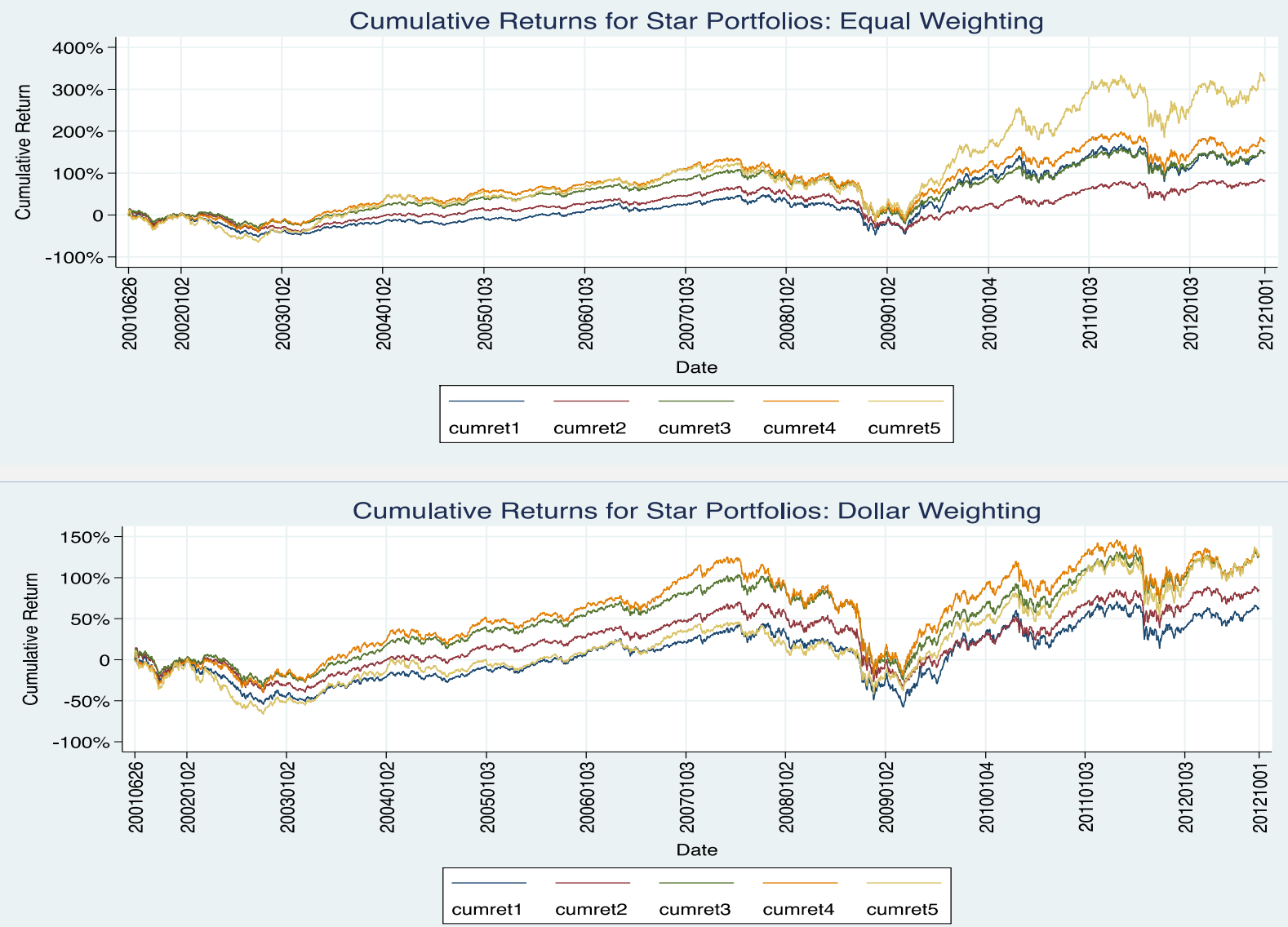

This figure shows the cumulative returns for portfolios formed by star rating for the period June 26, 2001 through October 1, 2012. Equal weighted portfolios are formed by calculating the arithmetic average return for all stocks carrying the specified ranking each day. Dollar weighted portfolios assume $\$ 1$ is invested in a stock as it enters a portfolio. The accumulated value of this investment is removed from the portfolio when the stock leaves the portfolio. The aggregate end of day value of all stocks in a specified star portfolio is then used to calculate the daily dollar weighted portfolio return. For both equal weighted and dollar weighted portfolios all rebalancing occurs at the end of the trading day. 
We start by examining overall portfolio risk. The annualized standard deviations for equally weighted 5- and 1star portfolios are $31.07 \%$ and $29.51 \%$ respectively. An F-test indicates that these risk measures are different at the 1\% level. Five-star returns are more volatile than 1-star returns for EW portfolios. However, a similar analysis of dollar weighted portfolios shows no significant difference in standard deviation for 5-star (29.80\%) and 1-star (30.42\%) portfolios.

What about a long-short portfolio formed by buying the 5-star portfolio and shorting the 1-star portfolio? This strategy would produce a cumulative return of $173.42 \%$, or an annualized return of $9.35 \%$. While these returns are inferior to those produced from a long-only 5-star portfolio, the annualized standard deviation of the longshort portfolio is only $15.07 \%$, materially lower than the 5-star portfolio's risk level. For the DW portfolios, the long-short portfolio provides cumulative returns of $65.51 \%, 4.58 \%$ annually with a standard deviation of $14.61 \%$.

\subsection{Risk-adjusted returns, equally weighted portfolios}

Perhaps there are other systematic differences between the returns generated by 5-star and 1-star stocks. Such style differences in these stocks and their related portfolio returns could explain the differential performance we observe. Fama and French (1993) show that there are other factors effective at explaining return. Their 3-factor model is now considered the standard method for calculating risk-adjusted returns. We also include a fourth factor, identified by Carhart (1997) that detects momentum effects on portfolio returns. The model we estimate appears below:

$$
\mathrm{R}_{\mathrm{it}}-\mathrm{R}_{\mathrm{ft}}=\alpha_{\mathrm{i}}+\beta_{\mathrm{i}}\left(\mathrm{RM}_{\mathrm{t}}-\mathrm{Rf} \mathrm{f}_{\mathrm{t}}\right)+\mathrm{si}_{\mathrm{i}} \mathrm{SMB}_{\mathrm{t}}+\mathrm{h}_{\mathrm{i}} \mathrm{HML}_{\mathrm{t}}+\mathrm{u}_{\mathrm{i}} U \mathrm{MD}_{\mathrm{t}}+\mathrm{e}_{\mathrm{it}}
$$

In the equation, $\mathrm{R}_{\mathrm{it}}-\mathrm{Rf}_{\mathrm{t}}$ and $\mathrm{RM}_{\mathrm{t}}-\mathrm{Rf}_{\mathrm{t}}$ represent the day $\mathrm{t}$ excess return on the selected portfolio and the market respectively. $\mathrm{SMB}_{\mathrm{t}}$ is the difference between returns for small cap and large cap, or "small minus big" securities during day t. The differential return between value stocks (high book-to-market) and growth stocks (low bookto-market) during day $\mathrm{t}$ is captured by HMLt. Finally, $U \mathrm{UD}_{\mathrm{t}}$, represents the difference between the better and worse performing stocks, or "up minus down" for day t. We estimate values for $\alpha_{i}, \beta_{i}, s_{i}, h_{i}$, and $u_{i}$ using historical data. The intercept, or $\alpha_{i}$ term, is interpreted as the risk-adjusted return for the selected portfolio.

Daily return estimates for factors, Rf, SMB, HML, and UMD are obtained from Kenneth French's data library. As we are interested in Morningstar's ability to identify relative winners and losers, our proxy for RM, the market return, is the equally weighted return for all star-rated securities. Table 3 provides the results of this 4 -factor regression analysis for EW portfolios.

The results for all years indicate that the 5-star portfolio generated a positive and significant daily alpha of 2 bps $(0.02 \%)$ per day. Average daily alphas for the remaining portfolios generally decline as we move from 5 -star to 1 -star. Betas are greater than one for the 1 and 5-star portfolios and less than one for others. This pattern persists for all subperiods examined with the exception of 2007-2009 where betas are much more evenly distributed across portfolios. Both the 1-star and 5-star portfolios exhibit positive and significant SMB coefficients. The strong significance of this coefficient for the 5-1 portfolio suggests that the 1-star portfolio has a more extreme exposure to small caps. Exposure to the remaining two factors is opposite and significant for the 1 and 5-star portfolios. The 1-star portfolio has a significant tilt toward value stocks (positive HML coefficient) while the 5-star portfolio focuses on growth stocks (negative HML coefficient).

\begin{tabular}{|c|c|c|c|c|c|c|}
\hline $2001-2003$ & 1-star & 2-star & 3-star & 4-star & 5-star & $5-1$ \\
\hline Alpha & $-0.00047^{*}$ & $-0.00032^{*}$ & 0.000033 & $0.00028^{*}$ & 0.00013 & 0.000537 \\
\hline Beta & 1.046662 & $0.92829^{* * *}$ & $0.8882^{* * *}$ & 1.011543 & $1.19608^{* * *}$ & $0.162637^{*}$ \\
\hline SMB & $0.200014^{* * *}$ & $0.06303^{* *}$ & $-0.16945^{* * *}$ & $-0.06931^{* * *}$ & $0.311129^{* * *}$ & 0.111699 \\
\hline HML & $-0.265^{* * *}$ & -0.0765 & $-0.0611^{* *}$ & $0.057881^{*}$ & $0.215478^{* * *}$ & $0.480697^{* * *}$ \\
\hline UMD & 0.065557 & $0.14124^{* * *}$ & $126146^{* * *}$ & $-0.00 \varepsilon$ & $-0.56015^{* * *}$ & $-0.62599^{* * *}$ \\
\hline 2004-2006 & 1-star & $2-s t$ & 3-star & $4-5$ & $\operatorname{ar}$ & $5-1$ \\
\hline Alpha & -0.00006 & -0.000036 & 0.000017 & 0.000067 & 0.000078 & 0.000023 \\
\hline Beta & $1.040769^{* * *}$ & $0.974953^{* *}$ & $0.96561^{* * *}$ & 1.007096 & $1.109133^{* * *}$ & $0.067973^{* *}$ \\
\hline SMB & $0.062662^{* * *}$ & $-0.05446^{* * *}$ & $-0.07978^{* * *}$ & $0.047405^{* *}$ & $0.23548^{* * *}$ & $0.173116^{* * *}$ \\
\hline HML & $-0.04332 *$ & 0.012189 & -0.00389 & 0.01085 & 0.012479 & 0.055026 \\
\hline UMD & $0.29156^{* * *}$ & $0.065294^{* * *}$ & $-0.05934^{* * *}$ & $-0.20106^{* * *}$ & $-0.17481^{* * *}$ & $-0.46929^{* * *}$ \\
\hline 2007-2009 & 1-star & 2-star & 3-star & 4-star & 5-star & $5-1$ \\
\hline Alpha & 0.000565 & $-0.00031^{*}$ & $-0.00012^{* *}$ & -0.000085 & 0.000155 & -0.00049 \\
\hline Beta & 0.993765 & $0.95671^{* * *}$ & $0.971761^{* * *}$ & 0.993913 & 0.999383 & -0.005512 \\
\hline SMB & $0.348388^{* * *}$ & $0.31936^{* * *}$ & 0.040285 & -0.01563 & $-0.07994^{* * *}$ & $-0.42799 * * *$ \\
\hline
\end{tabular}




\begin{tabular}{|c|c|c|c|c|c|c|}
\hline HML & $0.277143^{* * *}$ & $0.161053^{* * *}$ & $0.043614^{* * *}$ & $-0.00548^{* * *}$ & $-0.12563^{* * *}$ & $-0.40336^{* * *}$ \\
\hline UMD & 0.01595 & $0.150437^{* * *}$ & $0.045658^{* * *}$ & $-0.03097^{* * *}$ & $-0.12702^{* * *}$ & $-0.14362^{* * *}$ \\
\hline 2010-2012 & 1-star & 2-star & 3-star & 4-star & 5-star & $5-1$ \\
\hline Alpha & -0.00019 & 0.000058 & -0.000012 & -0.000044 & $0.000313^{* *}$ & $0.000494^{* * *}$ \\
\hline Beta & 1.007009 & $0.968147^{* * *}$ & $0.97894^{* * *}$ & $1.025707^{* * *}$ & $1.072872^{* * *}$ & $0.064713^{* * *}$ \\
\hline SMB & $0.252896^{* * *}$ & $0.084157^{* * *}$ & $-0.03364^{* * *}$ & $-0.05708^{* * *}$ & 0.010113 & $-0.24536^{* * *}$ \\
\hline HML & $-0.07017^{* *}$ & $-0.05082^{* * *}$ & 0.00626 & $0.053983^{* * *}$ & $0.068916^{* * *}$ & $0.139472^{* * *}$ \\
\hline UMD & $0.202739 * * *$ & $0.198697^{* * *}$ & $0.019586^{* * *}$ & $-0.1409 * * *$ & $-0.24851^{* * *}$ & $-0.45166^{* * *}$ \\
\hline All Years & 1-star & 2-star & 3-star & 4-star & 5-star & $5-1$ \\
\hline Alpha & -0.000038 & $-0.00016^{* *}$ & -0.000044 & 0.000042 & $0.000205^{*}$ & 0.000175 \\
\hline Beta & $1.038217^{* * *}$ & $0.946051^{* * *}$ & $0.942662^{* * *}$ & 0.992974 & $1.092388^{* * *}$ & $0.054186^{* * *}$ \\
\hline SMB & $0.257466^{* * *}$ & $0.159907^{* * *}$ & $-0.02194^{* * *}$ & $-0.02252^{* * *}$ & $0.036795^{* *}$ & $-0.22035^{* * *}$ \\
\hline HML & $0.087537^{* * *}$ & $0.066976^{* * *}$ & $0.072549 * * *$ & 0.00523 & $-0.25647^{* * *}$ & $0.34435^{* * *}$ \\
\hline UMD & 0.020623 & $0.109027^{* * *}$ & $0.04295^{* * *}$ & $-0.05327^{* * *}$ & $-0.1874^{* * *}$ & $-0.2083^{* * *}$ \\
\hline
\end{tabular}

This table shows results from a 4-Factor regression of the form: $R_{i t}-R_{f t}=\alpha_{i}+\beta_{i}\left(R M_{t}-R_{t}\right)+s_{i} S M B_{t}+h_{i} H M L_{t}+$ $\mathrm{u}_{\mathrm{i}} U \mathrm{UD}_{\mathrm{t}}+\mathrm{e}_{i t}$. The dependent variable is the daily return for an equally weighted star portfolio minus the risk-free rate.

The UMD factor indicates that the 1-star portfolio has a strong preference for stocks that have done well in the recent past. The 5-star portfolio indicates a contrarian approach, favoring stocks that have not performed well. This result is likely an artifact of the rating process. Recall that stocks are evaluated on the relationship between Morningstar's estimate of fair value and the actual market value.

The 5-star portfolio contains stocks trading at the greatest discount to fair value, the most undervalued stocks. Conversely, 1-star stocks are the most overvalued stocks based on Morningstar's approach. Unlike market prices, the estimate of fair value does not change daily. This means that the majority of stocks upgraded to 5 -star status have likely experienced a recent market price decline. Similarly, stocks downgraded to 1-star status have likely experienced a recent increase in market price. This is consistent with the positive UMD factor for the 1-star portfolio and the negative value for the 5 -star portfolio.

More careful analysis of results shown in Table 3 indicate that the subperiod from 2007-2009 had a large influence on the overall results. This period captures the global financial crisis and the concurrent decline in U.S. equity markets. During this 3-year period, both 1-star and 5-star stocks produced positive alphas but neither is significant at a meaningful level. The SMB coefficient for the 5-star portfolio was negative in this period indicating a shift in style from small cap to large cap stocks. In 3 of 4 subperiods, the HML coefficients indicate a preference toward value and growth stocks for the 5-star and 1-star portfolios respectively. However, this relationship reversed in the 2007-2009 period. Furthermore, the significance of the reversal was large enough to influence the overall result. To examine these style spikes and transitions, we ran a series of overlapping 252 day Fama-French 4 -factor regressions using the daily returns for the 1 through 5 -star EW portfolios. The coefficients for these regressions are shown in Figure 2.

The Fama-French alphas for each of the five EW portfolios are shown in the first panel of Figure 2. The 5-star alpha is generally above the 1 -star alpha. The major exception occurs from the last half of 2008 through early 2009 when the 1-star alpha exceeds the 5-star alpha. While the 5-star portfolio outperformed the 1-star portfolio in absolute terms in 2008 (see Table 2), it was unable to do so on a risk-adjusted basis during much of that year. This result was not uncommon for quantitative investment strategies during this period of time.

Rolling betas (second panel of Figure 2) generally show a downward drift for the 5-star portfolio before stabilizing between 1.0 and 1.1 in the last half of 2009. While the 1-star beta is generally below the 5 -star beta, there are exceptions during 2007 and 2009 when the 1-star beta showed high volatility.

The third panel of Figure 2 shows the SMB coefficient for the rolling Fama-French regressions. This illustration clearly shows the change in style for the 1 and 5-star portfolios. For most of the period from 2001 to 2007, both of these portfolios had a positive SMB coefficient indicating a preference for small cap stock for both portfolios. By mid-2007, both portfolios appear to have an SMB coefficient close to zero. At this point, there is a clear change in strategy for the 5-star portfolio indicated by the change in sign of the SMB coefficient and a simultaneous upward spike in this measure for the 1-star portfolio. From mid-2007 on, the 5-star portfolio generally maintained a negative or neutral SMB coefficient. 
Figure 2: 252 Day Fama-French 4-Factor Regressions for Equally Weighted Portfolios
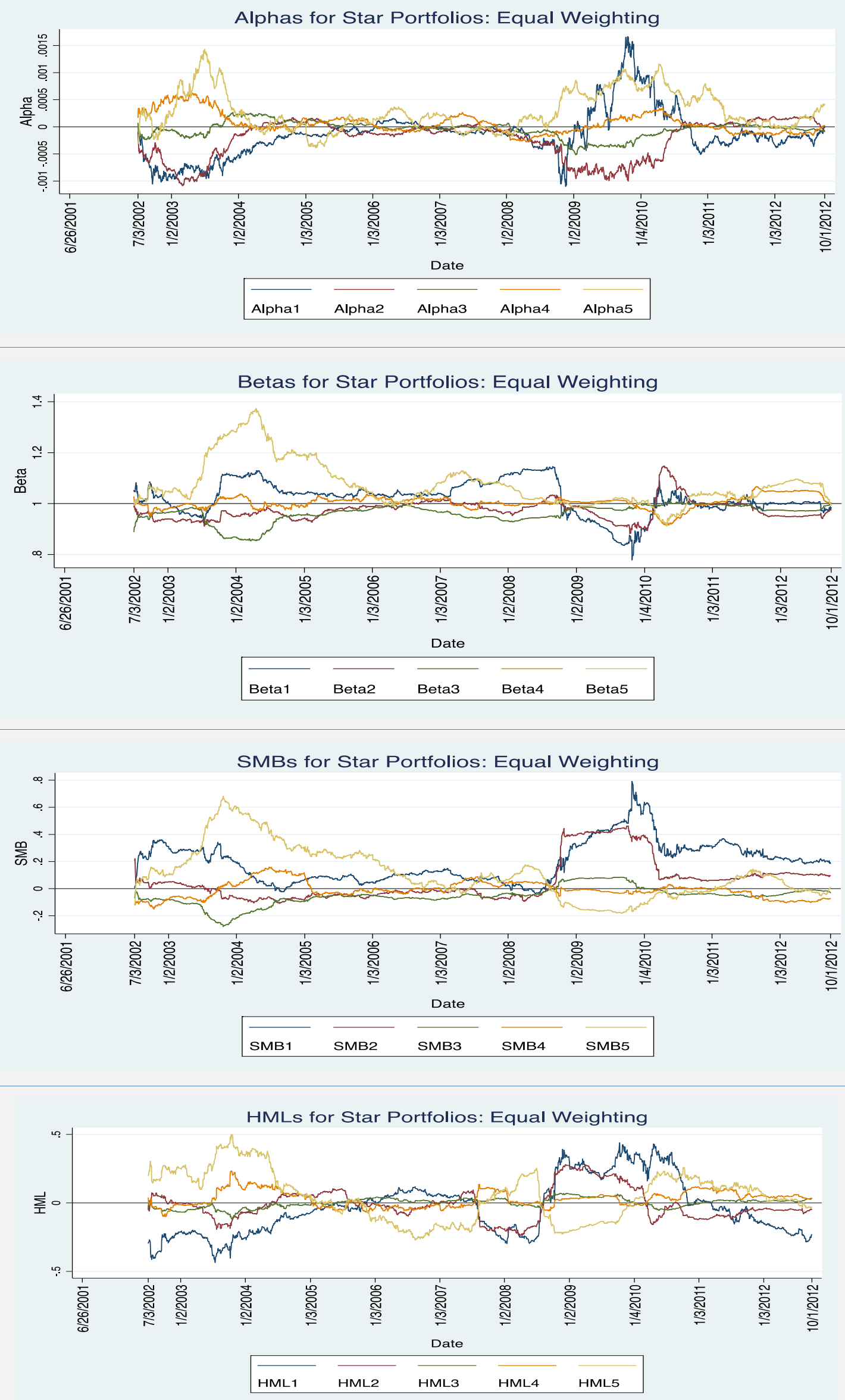


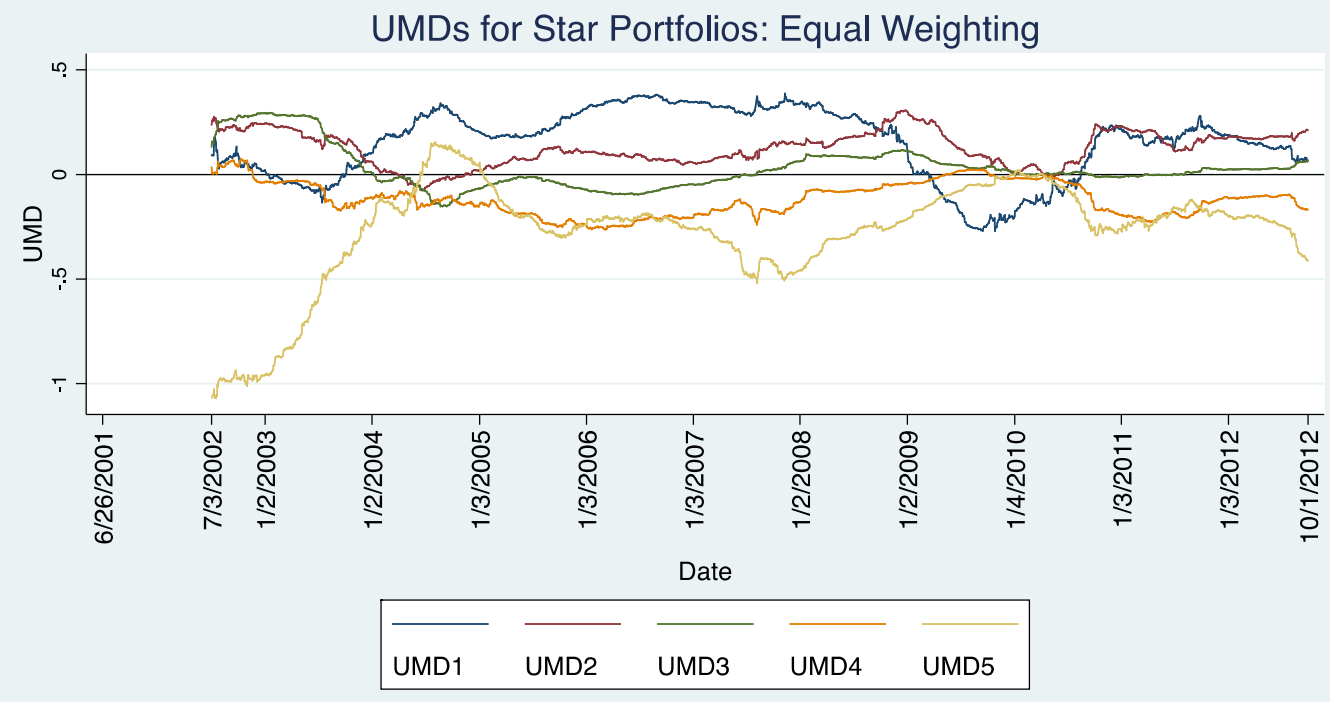

Panels A through E display the coefficients derived from overlapping 252 day 4-factor regressions of the form: $\mathrm{R}_{\mathrm{it}}$ $-\mathrm{R}_{\mathrm{ft}}=\alpha_{\mathrm{i}}+\beta_{\mathrm{i}}\left(\mathrm{RM}_{\mathrm{t}}-\mathrm{Rf}_{\mathrm{t}}\right)+\mathrm{s}_{\mathrm{i}} S \mathrm{BB}_{\mathrm{t}}+\mathrm{h}_{\mathrm{i}} \mathrm{HM} \mathrm{L}_{\mathrm{t}}+\mathrm{u}_{\mathrm{i}} \mathrm{UMD}_{\mathrm{t}}+\mathrm{e}_{\mathrm{it}}$. The dependent variable is the daily return for an equally weighted star portfolio minus the risk-free rate.

The last two panels of Figure 2 depict the HML and UMD coefficients for each of the five star portfolios. Both the 1-star and 5-star portfolio HML coefficients cross the horizontal axis numerous times and appear to have an inverse relationship. The UMD coefficients are much more consistent, remaining negative for the 5 -star portfolio with minor exceptions. The 1-star portfolio displays a similar pattern on the positive side. Again, this is consistent with the rating process described by Morningstar. Stocks with declining values are more likely to be undervalued and rising stocks are more likely to be overvalued.

\subsection{Risk-adjusted returns, dollar weighted portfolios}

The dollar weighted results shown in Table 4, indicate that the 1-star portfolio generated a negative and significant alpha of 2 bps $(0.02 \%)$ per day over the entire period of analysis. Unlike the alphas from our analysis of equal weighted returns, which increased monotonically from 1-star to 5-star, there is little variation in alphas for the various dollar weighted portfolios. Similar to the EW results, betas are greater than 1 for the 1 and 5-star portfolios and less for others. Other factor exposures are also similar to the analysis of EW portfolios. The 1-star portfolio appears exposed to small value stocks and the 5-star is exposed to large growth stocks. There is still a clear preference for stocks with positive momentum in the 1-star portfolio and negative momentum in the 5-star portfolio.

Similar to the analysis of EW portfolios, the 2007-2009 period has a strong influence on the overall results. The strong preference for large cap stocks (negative SMB) within this period offsets a strong preference for small caps during the period from 2001 to 2006.

A modest distinction between the EW and DW portfolios relates to the behavior of the HML coefficient. This factor is only significant during one sub-period, 2007-2009, when it indicates a preference for growth stocks in that portfolio. The HML coefficient for the 1-star portfolio exhibits the same behavior as in the analysis of EW returns.

\begin{tabular}{lrrrrrr}
\hline \multicolumn{7}{c}{ Table 4: Fama-French 4-Factor Regression Results (Dollar Weighted Portfolios) } \\
\hline 2001-2003 & 1 -star & 2 -star & 3-star & 4 -star & 5 -star & $5-1$ \\
\hline Alpha & $-0.0006^{* *}$ & -0.0003 & -0.000031 & 0.00015 & -0.00049 & 0.00004 \\
Beta & $1.063044^{* * *}$ & $0.931564^{* * *}$ & $0.887256^{* * *}$ & 1.019927 & $1.196592^{* * *}$ & $0.133678^{* * *}$ \\
SMB & $0.244108^{* * *}$ & 0.035971 & $-0.15458^{* * *}$ & $-0.07741^{* * *}$ & $0.254423^{* * *}$ & 0.010899 \\
HML & $-0.22343^{* * *}$ & $-0.08052^{*}$ & $-0.08008^{* * *}$ & 0.028313 & 0.039883 & $0.263539^{* * *}$ \\
UMD & $0.098655^{* *}$ & $0.200431^{* * *}$ & $0.158049^{* * *}$ & $0.073395^{* * *}$ & $-0.35558^{* * *}$ & $-0.45452^{* * *}$ \\
2004-2006 & 1 -star & 2 -star & 3 -star & 4 -star & 5 -star & $5-1$ \\
Alpha & -0.000024 & -0.000045 & 0.000033 & 0.000095 & 0.000002 & -0.00009 \\
Beta & $1.054582^{* * *}$ & $0.964383^{* * *}$ & $0.959741^{* * *}$ & 1.00492 & $1.101732^{* * *}$ & $0.046759^{*}$ \\
SMB & $0.053742^{* *}$ & $-0.05138^{* * *}$ & $-0.07761^{* * *}$ & $0.054236^{* * *}$ & $0.217775^{* * *}$ & $0.164331^{* * *}$ \\
HML & $-0.09087^{* * *}$ & 0.006633 & -0.02472 & 0.005628 & -0.01557 & 0.074529 \\
UMD & $0.374134^{* * *}$ & $0.074486^{* * *}$ & $-0.01935^{*}$ & $-0.18022^{* * *}$ & -0.2677 & $-0.40022^{* * *}$ \\
2007-2009 & 1 -star & 2 -star & 3 -star & 4 -star & 5 -star & $5-1$ \\
\hline
\end{tabular}




\begin{tabular}{|c|c|c|c|c|c|c|}
\hline Alpha & 0.000051 & -0.00026 & $-0.00024^{* * *}$ & $-0.00022^{* * *}$ & -0.00016 & -0.00015 \\
\hline Beta & $1.062309^{* * *}$ & $0.954757^{* * *}$ & $0.953051^{* * *}$ & $0.984086^{* * *}$ & $0.978386^{* * *}$ & $-0.08403^{* * *}$ \\
\hline SMB & $0.313069^{* * *}$ & $0.390897^{* * *}$ & $0.056557^{* * *}$ & -0.01136 & $-0.09072^{* * *}$ & $-0.40345^{* * *}$ \\
\hline HML & $0.272248^{* * *}$ & $0.231662^{* * *}$ & $0.060667^{* * *}$ & -0.01258 & $-0.12837^{* * *}$ & $-0.40121^{* * *}$ \\
\hline UMD & $0.084379 * *$ & $0.18333^{* * *}$ & $0.07196^{* * *}$ & -0.0066 & $-0.05891^{* * *}$ & $-0.14394^{* * *}$ \\
\hline $2010-2012$ & 1-star & 2-star & 3-star & 4-star & 5-star & $5-1$ \\
\hline Alpha & -0.0002 & 0.000023 & -0.000009 & $-0.00012^{* *}$ & $0.000211^{*}$ & $0.000405^{* *}$ \\
\hline Beta & $1.047495^{* * *}$ & $0.969574^{* * *}$ & $0.998718^{* * *}$ & $1.014953^{* * *}$ & $1.081813^{* * *}$ & $0.034319^{*}$ \\
\hline SMB & $0.288913^{* * *}$ & $0.112666^{* * *}$ & -0.00982 & $-0.05127^{* * *}$ & -0.01151 & $-0.30047^{* * *}$ \\
\hline HML & -0.00504 & $-0.0388^{* *}$ & -0.00717 & $0.046148^{* * *}$ & -0.00226 & 0.002796 \\
\hline UMD & $0.277353^{* * *}$ & $0.246288^{* * *}$ & $0.084469^{* * *}$ & $-0.08629 * * *$ & $-0.19247^{* * *}$ & $-0.46982^{* * *}$ \\
\hline All Years & 1-star & 2-star & 3-star & 4-star & 5-star & 5-1 \\
\hline Alpha & $-0.00021^{*}$ & $-0.00017^{* *}$ & $-0.000082^{* *}$ & -0.000032 & -0.000029 & 0.000108 \\
\hline Beta & $1.088811^{* * *}$ & $0.944657^{* * *}$ & $0.935125^{* * *}$ & $0.987131^{* * *}$ & $1.085408^{* * *}$ & $-0.00339 *$ \\
\hline SMB & $0.255151^{* * *}$ & $0.188087^{* * *}$ & -0.00738 & $-0.02192^{* * *}$ & 0.025653 & $-0.22918^{* * *}$ \\
\hline HML & $0.112998^{* * *}$ & $0.107952^{* * *}$ & $0.06811^{* * *}$ & -0.00205 & $-0.27281^{* * *}$ & $0.38614^{* * *}$ \\
\hline UMD & $0.084316^{* * *}$ & $0.133848^{* * *}$ & $0.074487^{* * *}$ & $-0.01185^{* *}$ & $-0.09494^{* * *}$ & $-0.17953^{* * *}$ \\
\hline
\end{tabular}

This table shows results from a 4-Factor regression of the form: $R_{i t}-R_{f t}=\alpha_{i}+\beta_{i}\left(R_{t}-R_{t}\right)+s_{i} S M B_{t}+h_{i} H M L_{t}+$ $\mathrm{u}_{\mathrm{i}} U \mathrm{UMD}_{\mathrm{t}}+\mathrm{e}_{\mathrm{it}}$. The dependent variable is the daily return for a dollar weighted star portfolio minus the risk-free rate.

\subsection{Transaction costs}

Recall that the 5-star DW portfolio generated an average annual return of $13.66 \%$. But this return does not reflect costs associated with the significant amount of trading necessary to maintain a portfolio of purely 5-star stocks. During the entire period of analysis, the average number of daily trades needed to maintain the 5-star portfolio is 7.6, or approximately 1914 trades per year. To assess the impact of this activity, we use a simple approach to model transaction costs. We assume that a retail investor can execute a $\$ 10,000$ trade for $\$ 10$ and then scale that to our $\$ 1$ trade. This results in a fixed transaction cost of $\$ 0.001$ that we apply to each purchase and sale. When we account for this cost in the 5-star dollar weighted returns, we end up with an annualized return of 7.02\%.

The long-short portfolio designed to capture the return difference between the 5-star and 1-star stocks is even more severely affected by the recognition of this modest transaction cost. This portfolio's annual return declines from $9.35 \%$ to $3.02 \%$ when transaction costs are included. If the fixed transaction cost is increased to $\$ 0.0029$ per trade, the net return on this portfolio is reduced to $0.00 \%$.

\subsection{Conclusion}

The objective of this paper has been to examine the portfolio returns earned by investing in portfolios of stocks categorized by Morningstar's 5-star rating system for individual stocks. Morningstar, Inc. is a well-established provider of information and analysis on a wide variety of financial investments. If markets are semi-strong form efficient, then we would not expect to find risk-adjusted outperformance from trading on Morningstar ratings. While the preponderance of evidence shows that markets are semi-strong form efficient, some prior studies do document evidence of abnormal returns from various trading strategies, including some from following the advice of select investment newsletters or information providers. Our results provide some perspective on the overall value of Morningstar's stock ratings service. The results show that the Morningstar ratings are able to effectively able to distinguish between the most overvalued (1-star) and undervalued (5-star) stocks over the period of our study.

Using equally-weighted returns, over the 2001-2012 period, the 5-star portfolio earns a cumulative return of $322.26 \%$, or $13.66 \%$, annualized, compared to $148.86 \%$, or $8.44 \%$ annualized for the 1 -star portfolio, for a difference of $173.4 \%$, or $5.22 \%$ annualized. For a dollar-weighted returns, the 5 -star portfolio earns a cumulative return of $127.89 \%$, or $9.09 \%$ annualized, compared to $62.37 \%$, or $5.25 \%$ annualized for the 1 -star portfolio, for a difference of $65.52 \%$, or $3.84 \%$ annualized. Using a four-factor model to adjust for risk, and using equallyweighted returns, we find that the 5 -star portfolio generated a positive and significant alpha of 2 bps ( $0.02 \%)$, and that alphas decline monotonically for the other portfolios. The 5-star portfolio tilts to large, growth stocks, while the 1-star portfolio tilts to small, value stocks. The 1-star portfolio shows a preference for stocks that have done well in the past, while the 5-star portfolio indicates a contrarian approach, favoring stocks that have not performed well in the recent past. Using dollar-weighted returns in the risk analysis, yields slightly different results. 
These results provide evidence that the Morningstar stock rating system does allow an investor to build a portfolio that outperforms the market average over a long period of time. The results are not as strong after adjusting for portfolio risk, but there is still some evidence of outperformance on a risk-adjusted basis. The risk factors also vary across the different portfolios and the results exhibit some variation over time. It should also be noted that the investment strategies examined herein required a significant amount of trading activity and therefore would incur transactions costs. We show that a modest transaction cost will reduce, but not eliminate, the benefits available from a trading strategy based on the ranking system.

Overall, the results are consistent with Morningstar analysts providing valuable analysis. They should be of interest to both institutional and individual investors seeking to develop an active, or alpha-generating, investment strategy, to those interested in an unbiased and scientific analysis of this Morningstar service, and to those interested in studies of the impact of analysts' recommendations.

\section{References}

Barber, B., R. Lehavy, M. McNichols, B. Trueman, (2001). Can Investors Profit from the Prophets? Security Analysts Recommendations and Stock Returns, Journal of Finance, 61(2), 531-563. http://dx.doi.org/10.1111/00221082.00336

Barber, B., R. Lehavy, M. McNichols, B. Trueman. (2010). Ratings changes, ratings levels, and the predictive value of analysts' recommendations, Financial Management, 39(2), 533-553. http://dx.doi.org/10.1111/j.1755053X.2010.01083.X

Black, F. (1973). Yes, Virginia, There Is Hope: Tests of the Value Line Ranking System, Financial Analysts Journal, 29(5), 10-14+.

Blake, C., M. Morey. (2000). Morningstar Ratings and Mutual Fund Performance, Journal of Financial and Quantitative Analysis, 35(3), 451-483. http://dx.doi.org/10.2307/2676213

Bolster, P., E. Trahan, A. Venkateswaran, (2012). How Mad Is Mad Money: Jim Cramer as a Stock Picker and Portfolio Manager, Journal of Investing, 22(2), 27-39. http://dx.doi.org/10.3905/joi.2012.21.2.027

Carhart, M. (1997). On Persistence in Mutual Fund Performance, Journal of Finance, 52(1), 57-82. http://dx.doi.org/10.1111/j.1540-6261.1997.tb03808.x

Del Guericio, D., P. Tkac, (2008) . Star Power: The Effect of Morningstar Ratings on Mutual Fund Flow, Journal of Financial and Quantitative Analysis, 43(4), 907-936. http://dx.doi.org/10.1017/S0022109000014393

Dewally, M., (2003). Internet Investment Advice: Investing with a Rock of Salt, Financial Analysts Journal 59(4), 65-77. http://dx.doi.org/10.2469/faj.v59.n4.2546

Dorsey, P. (2008). FAQ: The Morningstar Rating for Stocks. Retrieved from: http://news.morningstar.com/articlenet/article.aspx?id=4982

Fama, E., K. French. (1993). Common Risk Factors in the Returns on Stocks and Bonds, Journal of Financial Economics, 33(1), 3-56. http://dx.doi.org/10.1016/0304-405X(93)90023-5

Hall, T., J. Tsay. (1988). An evaluation of the performance of portfolios selected from Value Line Rank One stocks: 1976-1982, Journal of Financial Research 11(3), 227-240. http://dx.doi.org/10.1111/j.14756803.1988.tb00084.x

McLean, R., J. Pontiff. (2014). Does Academic Research Destroy Stock Return Predictability?. Working paper. Retrieved from: http://ssrn.com/abstract=2156623.

Metrick, A. (1999). Performance evaluation with transactions data: The stock selection of investment newsletters. Journal of Finance 54(5), 1743-1775. http://dx.doi.org/10.1111/0022-1082.00165 